\title{
Reflexões sobre o desentendimento entre línguas
}

\author{
Simone Hashiguti (HASHIGUTI, Simone) \\ Professora Doutora da Universidade Federal de Uberlândia - UFU \\ simonehashiguti@yahoo.com
}

\begin{abstract}
Resumo
O objetivo deste texto é refletir a respeito do desentendimento nas relações interpessoais entre falantes de diferentes línguas por uma perspectiva discursiva de linguagem. Tomando como material inicial de reflexão uma cena do filme de Oshima (1982), Furyo: em nome da honra, discute-se o desentendimento como efeito do desencontro de sentidos para um mesmo fato de linguagem a partir de gestos de interpretação de sujeitos que se filiam a diferentes formações discursivas. A formação discursiva é compreendida, na teoria da Análise de Discurso (com referência a autores como Michel Pêcheux, por exemplo), como aquilo que define o que pode e deve ser dito em uma dada posição numa dada conjuntura, ou seja, como o que determina o sentido e as formas de dizer em uma situação localizável histórica, política e socialmente. Analisam-se, além do filme, outros fragmentos de textos: relatos de imigrantes (e de seus descendentes ou parentes) e de alunos de línguas estrangeiras sobre situações de desentendimento. Abordam-se, também, aspectos relativos ao desentendimento no contexto de sala de aula de línguas. Por fim, aponta-se que, na relação entre línguas, os desentendimentos se referem ao historicamente (interdiscursivamente) possível para cada língua.
\end{abstract}

Palavras-chave: desentendimento, formação discursiva, línguas estrangeiras, cultura.

\begin{abstract}
This paper aims at reflecting on the notion of misunderstanding between languages from a discursive perspective. Taking a scene from the film by Oshima (1982): "Merry Christmas, Mr. Lawrence" as the starting point of our discussion, misunderstanding is discussed as an effect of moves of interpretation of subjects positioned in different discursive formations. Discursive formation is a concept in Discourse Analysis (referred to by the philosopher Michel Pêcheux, for example) that relates to what determines what is to be said and how at a certain subjective position within a certain situation. That is, it determines the meaning and the formulation as they are produced, for it refers to the language and the subject in a situation that is historically, politically and socially constituted. Other kinds of texts are also examined, such as stories of misunderstandings told by immigrants (and their descendents or relatives) and by foreign language students. Aspects involving misunderstandings in the language classroom are also discussed. It is concluded that the misunderstandings that occur, when speakers of different languages come into contact, are due to what is historically (interdiscursively) possible in each language.
\end{abstract}

Key-words: misunderstanding, discursive formation, foreign languages. 


\section{Introdução}

O desentendimento é um efeito sempre possível nas inter-relações entre falantes de uma mesma língua e entre falantes de línguas distintas. Não porque, como lembra Rancière (1996:12), possa haver desconhecimento ou ignorância por parte dos interlocutores sobre o que se fala, mas porque, com relação aos sentidos, parece sempre haver um momento possível de litígio acerca do objeto da discussão, uma disputa que tem a ver com a situação dos interlocutores, a impossibilidade de concordância ou de chegada a um mesmo sentido. Essa situação de constante tensão é própria do funcionamento da linguagem. Neste texto, a proposta é pensar, a partir da análise de materiais variados - fragmentos de um filme; entrevistas com alunos de línguas estrangeiras; relatos e notas, coletados em pesquisa anterior sobre processos de aprendizagem de línguas ${ }^{1}$ - a noção de desentendimento sob uma perspectiva discursiva, que considera que o sentido é produzido por sujeitos que são posições discursivas, historicamente constituídas. Compreendendo que os sentidos das palavras são atribuídos através das posições ocupadas pelos sujeitos, filiados a formações discursivas, o sentido de desentendimento será abordado juntamente com as análises apresentadas.

\section{Uma questão de honra, ou a honra em questão}

O filme "Furyo: em nome da honra", 2 do diretor Nagisa Oshima retrata a rotina de um campo de guerra na Ilha de Java, em 1942, onde soldados britânicos, entre outros, são prisioneiros dos japoneses. Durante a narrativa do filme, situações de conflito entre japoneses e ingleses são postas em jogo por meio de diálogos entre oficiais de alto escalão de ambas as partes: o Sargento Hara (Takeshi Kitano), o Capitão Yonoi (Ryuichi Sakamoto), o Coronel John Lawrence (Tom Conti) e o Major Jack Celliers (David Bowie) travam discussões sobre a vergonha, o medo, os costumes e as diferenças nas condutas de guerra e na vida civil. Esses diálogos são atravessados por uma questão latente no filme: o sempre desentendimento entre os interlocutores com a fracassada tentativa de intercompreensão. A honra e os gestos que a representam são o mote principal. Tanto ingleses quanto japoneses sabem que ela se coloca como essencial para os dois lados, mas não podem (historicamente) compartilhar os mesmos sentidos. Com exceção do personagem de Conti, o Cel. Lawrence, que transita bem entre os sentidos possíveis para uma e outra língua, há um espaço entre eles construído pelas diferentes memórias de língua e história, um espaço de desconforto, fascínio, admiração e ao mesmo tempo repúdio pelo que se lhes mostra estranho. Retomo os diálogos abaixo, transcritos de algumas das cenas, para dar visibilidade à situação de desentendimento:

Fragmento de cena 1:

Oficial Japonês: — Responda! Seu nome é Jack Celliers?

Maj. Celliers: - Já respondi essa questão mais de cem vezes. (...)

Oficial: - Nunca daria um nome falso?

\footnotetext{
${ }^{1}$ Pesquisa de Mestrado na Universidade Estadual de Campinas. Cf. Hashiguti, 2003.

${ }^{2}$ Do japonês: Senjō no merii kurisumasu, produzido em 1982, baseado no romance de Sir Laurens Van der Post The seed and the sower, Penguin, Harmondsworth, 1966.
} 
Celliers: - Deixe-me fazer uma pergunta: por que um homem à beira da morte mentiria?

Oficial: - Um soldado japonês capturado daria um nome falso. Mas, na verdade, um soldado japonês não se deixaria capturar. Ele preferiria a morte.

Celliers: - Pois bem, eu não sou japonês.

Fragmento de cena 2:

Sarg. Hara: - Lawrence, por que continua vivo? Eu o admiraria mais se você morresse. Um oficial tão bom. Como suporta a vergonha?

Cel. Lawrence: - Para nós não é vergonha. Ser prisioneiro é contingência de guerra. Mas não estamos felizes. Queremos fugir. Vencer vocês.

Sarg. Hara: - Conversa fiada!

Cel. Lawrence: - Não, queremos vencer! Este campo não é o fim de tudo. Não nos mataremos. É covardia.

Sarg. Hara: - Têm medo de morrer!

Nesses fragmentos, o desentendimento não se localiza na língua enquanto estrutura falada com mais ou menos marcas de estrangeiridade (e.g. sotaque, marcas morfossintáticas). No fragmento de cena 1, o diálogo entre eles ocorre em inglês, e no fragmento de cena 2, ele se dá em japonês. O que se mostra nessas discussões são os diferentes sentidos de honra e vergonha que circulam para o oficial japonês, Celliers, Hara e Lawrence. Para um sujeito japonês, render-se ao exército inimigo (Celliers havia se rendido), ou ser capturado por ele, seria tão vergonhoso que, ou seria preciso recorrer a uma mentira ou a morte, daí a repetição incessante da pergunta do nome de Celliers a ele e os questionamentos de Hara a Lawrence: “ - Por que continua vivo?” [...] “Como suporta a vergonha?” Para Celliers, essas possibilidades nem mesmo se configurariam, por isso daí sua indagação: “- Por que um homem à beira da morte mentiria?” Para Lawrence, era clara a discrepância do sentido que um inglês atribuiria ao suicídio: uma “covardia”, da mesma forma que para Hara o não-suicídio seria inconcebível. A honra e as maneiras de representá-la eram, portanto, diferentes para os sujeitos das diferentes línguas, e apesar das muitas discussões, da observação mútua no campo de guerra, não conseguiam chegar aos mesmos sentidos uns dos outros. $\mathrm{O}$ desentendimento estava no fato de que eram posicionados em lugares diferentes, impossibilitados historicamente, assim como compreendido discursivamente, de produzirem os mesmos sentidos de seus interlocutores.

\section{Formações discursivas e desentendimento}

A menção a uma impossibilidade histórica de produção de sentidos pode ser entendida a partir do conceito de formação discursiva da Análise de Discurso. A formação discursiva, segundo Pêcheux (1988, p. 160), se refere ao que é da ordem da regularização de sentidos e determina o que pode e deve ser dito em uma dada posição numa dada conjuntura. Como explica Orlandi (2005, p. 43), a perspectiva discursiva entende que as palavras não guardam em si os sentidos, pois eles derivam das formações discursivas em que se inscrevem, e estas são regionalizações do interdiscurso (memória discursiva), que é a possibilidade histórica do dizer, saber discursivo de língua e de linguagem que constitui o sujeito. 
Courtine (1981), por sua vez, estende o conceito de formação discursiva para o de memória discursiva, reconhecendo-os como análogos ao discutir o "modo de existência histórica do enunciado". Como concorda Payer (2006), para que haja regularização de sentidos deve haver memória e repetição e, portanto, a analogia se fundamenta. Esse conceito incorpora o aspecto dinâmico de inter-relação/constituição entre as formações discursivas dentro de uma historicidade constitutiva do sujeito sem perder a noção do espaço determinante do sentido, que é buscado pelo analista para poder compreender o funcionamento discursivo. Do ponto de vista dese estudo, a analogia também permite uma melhor compreensão sobre a questão do desentendimento entre línguas, pois diferentes línguas têm memórias discursivas distintas que constituem os sujeitos como sujeitos de língua(gem) e possibilitam sentidos que, por vezes, só são apreensíveis (possíveis) em suas próprias discursividades. $\mathrm{Na}$ relação entre línguas, os desentendimentos se referem ao historicamente (interdiscursivamente) possivel para cada língua.

Oshima trabalhou toda a sua narrativa nesse espaço de tensão de diferentes sentidos, dando visibilidade, a cada momento, nos gestos, nos diálogos, ao que distingue as duas posições subjetivas enquanto originárias de diferentes países e línguas. Ele mostrou o desentendimento como condição imanente dessa interrelação. Como lembra Rancière (1996:11), o desentendimento não se instaura numa situação em que um sujeito diz "branco" e o outro entende "preto", mas quando ele diz "branco" e o outro entende "branco", mas com outro sentido. A honra dos soldados japoneses e ingleses, no filme de Oshima, é este branco de sentidos desencontrados. Os primeiros se inscrevem em uma formação discursiva em que a honra é morrer. Os segundos, em uma formação discursiva em que a honra é manter-se vivo.

Esse desencontro de sentidos é a situação de muitos imigrantes que vivem em países de línguas diferentes das originárias. O desentendimento habita muitas de suas relações com os nativos do país de adoção e com seus próprios descendentes, nascidos e crescidos nesse país. O exemplo a seguir vai ao encontro dessa situação. Um imigrante japonês, que vive no Brasil há setenta e cinco anos ${ }^{3}$, comenta que sempre entra em discussão com sua nora, brasileira, não descendente de japoneses, porque ela não tem respeito por ele. Ele exemplifica seu ponto de vista com um relato sobre uma fala dela que o fez "sentir-se ofendido":

\section{M: - Enton, outro dia era disse pra mim: "-Que forga, hein, vô??. Isso é coisa de falá pra mim, pra argúem da minha idade? Onde já se viu? Tem que ter respeito. ${ }^{4}$}

Segundo a nora, entretanto, seu comentário quis ter tido o sentido de humor (e por esse motivo ela argumentou o uso de "forga" ao invés de "folga”), uma brincadeira em alusão a um momento de descanso do sogro, que estava deitado confortavelmente em uma rede. Para ela, seu dizer era uma brincadeira típica de brasileiros entre si, enfatizando o aspecto positivo de um momento de repouso. Para ele, porém, que se inscrevia, naquele momento, na posição-sujeito japonês, esse sentido não poderia ser. Na formação discursiva japonesa de respeito aos mais velhos, a brincadeira da nora teve um sentido de contravenção. Entre as inscrições em diferentes formações

\footnotetext{
${ }^{3}$ le veio para cá com dois anos e meio, tendo vivido até a adolescência em colônia japonesa no Estado do Paraná.

${ }^{4}$ Dado coletado através de entrevista feita pela pesquisadora em junho de 2006. O primeiro “era”, no fragmento, representa sua pronúncia da palavra “ela”.
} 
discursivas desses dois sujeitos, reside o eterno conflito de sentidos, o desentendimento entre as posições-sujeito japonês e não-japonês. ${ }^{5}$

O desentendimento, portanto, é, em muitos casos de relações entre línguas, uma impossibilidade (da ordem do interdiscurso) de compreensão de um sentido pela não inscrição em uma mesma formação discursiva. Não é uma incapacidade cognitiva, mas uma impossibilidade histórico-constitutiva da posição-subjetiva ocupada na circunstância de enunciação.

\title{
O desentendimento na sala de aula de línguas
}

\author{
Alunas de um curso de inglês relataram em entrevista que: \\ G: - Nossa, quando a gente tem aula com a K, nós não entendemos nada. Ela \\ complica tudo na hora de explicar. \\ S: - É verdade, quando a P dá aula, é muito mais fácil. Ela dá exemplos que a \\ gente entende. A K fala, fala e a gente fica boiando. \\ $\mathrm{G}:-\dot{E}$, o jeito dela é diferente. ${ }^{6}$
}

Uma possibilidade de compreensão do desentendimento com $\mathrm{K}$ e da "maior facilidade de entendimento" com P das alunas é a inscrição em formações discursivas distintas. P era uma professora de inglês brasileira, que cresceu e vive no Brasil, enquanto $\mathrm{K}$ era uma professora australiana recém-chegada ao país. Ao explicar seus tópicos, $\mathrm{K}$ falava de um lugar diferente do ocupado pelas alunas. O que elas não "entendiam" era o que se inscrevia em formações discursivas nas quais não se identificavam. A "maior facilidade" das aulas de P, por outro lado, poderia ser o encontro das posições ocupadas, a inscrição em redes de sentido, em formas de dizer, que pertencem a uma memória discursiva que as constitui, professora e alunas, como sujeito. K, nesse jogo de sentidos, era a que falava do lugar do sentido e dos modos inacessíveis historicamente ("nós (posição-sujeito brasileiro) não entendemos nada”, "o jeito dela é diferente.”).

Além de casos de desentendimento e estranhamento como esses na sala de aula de línguas, um outro exemplo tem a ver com os sentidos atribuídos ao silêncio do aluno, isto é, aos momentos de não-verbalização. Muitos professores de línguas estrangeiras vêem nesses momentos o que chamam de "indisposição dos alunos para realizarem os exercícios orais”, o que faz com que se “desdobrem para tentar achar atividades que os impulsionem a falar". 7 Não falar, entretanto, pode ter diferentes sentidos, a partir de diferentes formações discursivas. Para o professor que se inscreve na formação discursiva em que falar significa aprender (geralmente relacionada às tendências de abordagens comunicativas no ensino de línguas ${ }^{8}$ ), a não verbalização da língua é um “problema de aprendizagem”. Para alguns alunos, porém, ter que falar é o que incomoda:

\footnotetext{
${ }^{5}$ A Análise de Discurso reconhece o sujeito como posição-sujeito no discurso. Como discorre Orlandi (2005, p. 49): “[...] o sujeito discursivo é pensado como "posição” entre outras. Não é uma forma de subjetividade, mas um "lugar” que ocupa para ser sujeito do que diz (M. FOUCAULT, 1969): é a posição que deve e pode ocupar todo indivíduo para ser sujeito do que diz”.

${ }^{6}$ Entrevista realizada em 2002, com alunos de uma escola de idiomas na cidade de Campinas.

${ }^{7}$ Dados coletados em conversas informais com professores de inglês na cidade de Campinas em 2002.

${ }^{8}$ Para uma discussão sobre métodos e abordagens de ensino de línguas estrangeiras, vide Coracini, 1997.
} 
C: - (Na aula de língua inglesa) Eu sinto liberdade para falar mentira à vontade, assim pelo menos alguma coisa é falada. [...] Eu não gosto de conversar em dupla com aluno/a, pois é muito vexante. ${ }^{9}$

“Falar mentira” na língua estrangeira é para C a forma de se identificar com a posição-sujeito aluna, na qual ela deve cumprir minimamente ("pelo menos alguma coisa é falada”) os exercícios de sala de aula. Mas o gesto de falar, de ter que se interrelacionar oralmente com o outro, é para ela um sofrimento, sua imagem fica fragilizada, a imagem que acha que o outro faz dela quando fala (“é vexante”). ${ }^{10}$ Como é possível compreender na seqüência do fragmento, a língua estrangeira não é, para ela, para ser falada para o outro, mas para ela mesma:

\section{C: - As aulas (de inglês) são muito gostosas. Os temas despertam interesse e são muitas vezes aquilo sobre o que eu estou passando. É incrivel, mas aconteceu muitas vezes. Discutir sentimentos, psicologia é mais fácil em outra língua. Coisas que parecem banais ganham relevo em outra língua e podem ser discutidas como importantes (como na verdade são quando se quer desabafar).}

O que a língua estrangeira possibilita a $C$ é a discussão de sentidos que não “podem” ser discutidos na língua materna, não por uma impossibilidade histórica de sentidos, de sentidos que não a constituem, mas de sentidos interditados na língua materna por sua característica fundadora. A língua estrangeira para $\mathrm{C}$ e para muitos sujeitos é inconscientemente significada como uma possibilidade de completude subjetiva, de formulação de sentidos que a habitam, mas que são abafados, proibidos na língua materna ${ }^{11}$, não podendo nela ser formulados.

Na língua estrangeira, diferentemente, a interdição, a lei da palavra paterna não se coloca, e o sujeito muda de posição-subjetiva, tendo a impressão da "liberdade" de sentidos, da possibilidade de falar ou significar o que são tabus na língua materna ("mentira”, "sentimentos"), assuntos imaginariamente tidos como "banais" ("Coisas que parecem banais ganham relevo em outra lingua e podem ser discutidas como importantes. (como na verdade são quando se quer desabafar)”.). Tem-se aí, na relação entre línguas para $\mathrm{C}$, duas posições-sujeito: a posição-sujeito $\mathrm{C}$, interditada pela-na língua materna, que sente vergonha ("é vexante”) de falar, e a posição-sujeito C que pode dizer quase tudo (sente liberdade para falar mentira à vontade", "sentimentos, psicologia").

O silêncio, portanto, em alguns momentos na sala de aula, significa outra coisa que a não inserção no processo de aprendizagem, como poderia depreender o professor. Ele é uma formulação ${ }^{12}$ que resulta da inscrição do sujeito em uma formação discursiva

\footnotetext{
${ }^{9}$ Dados extraídos de relato escrito presente em Hashiguti, 2003. Reproduzidos ipsis litteris.

${ }^{10}$ Pêcheux (1983) aponta que, no discurso, há o um jogo incessante de imagens entre os interlocutores, projeções a partir das relações de força, que determina os dizeres. Essas formações imaginárias se referem às imagens que o sujeito faz de si mesmo (IA(A)), de seu interlocutor (IA(B)), do referente (IA(R)), da imagem que acha que seu interlocutor tem dele (IA(B(A))), de si (IA(B(B)) e do referente (IA(B(R))).

${ }^{11}$ Segundo Melman (1992), que faz uma leitura psicanalítica da relação entre as línguas materna e estrangeira, o sujeito de desejo, de desejo do outro, não tem acesso, na língua materna, a determinados sentidos porque a condição para que venha a ser sujeito é a interdição, a palavra paterna que interdita a mãe e instaura a incompletude constitutiva.

${ }^{12}$ Assim como se pensa em formulações verbais, pensa-se o silêncio como formulação. Como aponta Orlandi (2002:12), o silêncio não deve ser visto por um sentido negativo na relação com o que é verbalizável. Ele é linguagem e tem sentido no discurso.
} 
na qual a língua estrangeira é o lugar onde sentidos que urgem de significação são permitidos e podem ser falados pelo sujeito para si próprio.

\section{Conclusão}

A breve retomada de fragmentos de histórias reais e de textos de ficção (que não deixam de ser reais, se pensados pelo viés da possibilidade histórica) teve como objetivo explorar o tema do desentendimento enquanto desencontro de sentidos por inscrições subjetivas em formações discursivas distintas. Abordou-se a questão das diferenças discursivas entre línguas, enfatizando-se o caráter constitutivo da memória discursiva, e também o desentendimento dentro de uma mesma língua, já que é efeito desse funcionamento na produção de sentidos. Discutiu-se, com base em dados coletados em sala de aula de língua estrangeira, o silêncio como formulação no discurso, que pode significar diferentes sentidos para diferentes posições-sujeito.

Acredita-se que tais considerações se colocam como importantes para as reflexões sobre os processos de aprendizagem de línguas por propiciarem a discussão dos próprios conceitos de sujeito e sentido a partir dos quais os professores e os métodos de ensino trabalham. A homogeneização buscada em (e imaginariamente sustentada por) muitos deles é posta em questão quando se discute o desentendimento, porque se percebe que a língua não significa da mesma forma para diferentes sujeitos, não havendo, portanto, a possibilidade de existência de uma forma única de ensino ou de uma única forma de entrada no processo de aprendizagem.

Além disso, a discussão apresentada pode contribuir com os estudos sobre interrelações pessoais por abordar um efeito de linguagem que é comum a qualquer sujeito em suas práticas linguageiras cotidianas, mas cuja forma de funcionamento é quase sempre negligenciada. Geralmente abordado sob o conceito de "diferenças culturais" em outras disciplinas sociais, o desentendimento ganha nelas o sentido de algo que pode ser resolvido se essas diferenças forem compreendidas. O que a noção de impossibilidade histórica de sentidos na constituição subjetiva traz à tona é, contrariamente, a possibilidade do eterno impasse, a impossibilidade, para alguns sujeitos, de chegar aos mesmos sentidos que outros. Essa parece ser, por exemplo, e como no filme de Oshima, a mola propulsora dos sempre existentes conflitos entre pessoas e povos.

\section{Referências}

CORACINI, Maria. J. R. F. Língua estrangeira e língua materna: uma questão de sujeito e identidade. Letras e Letras, Uberlândia, v. 14, n. 1. p. 153-169, jul./dez. 1997.

COURTINE, Jean. J. Quelques problémes théoriques et métodologiques em analyse du discours: à propôs du discours communiste adresse aux chretiennes. Langages, Paris, n. 62, 1981.

HASHIGUTI, Simone T. Subjetividade brasileira e aprendizagem de línguas estrangeiras: um estudo discursivo. 2003. 68f. Dissertação (Mestrado em Lingüística Aplicada) - Instituto de Estudos da Linguagem, Universidade Estadual de Campinas, Campinas, 2003. 
MELMAN, Charles. Imigrantes: incidências subjetivas das mudanças de língua e país. São Paulo: Escuta, 1992.

ORLANDI, Eni P. As formas do silêncio: no movimento dos sentidos. 5a. ed. Campinas: Editora da UNICAMP, 2002.

. Análise de Discurso: princípios e procedimentos. Campinas: Pontes, 2005.

PAYER, Maria Onice. Memória da língua: imigração e nacionalidade. São Paulo: Escuta, 2006.

PÊCHEUX, Michel. Semântica e discurso: uma crítica à afirmação do óbvio. Tradução de Eni Puccinelli Orlandi et al. Campinas: Editora da Unicamp, 1988.

Discurso: estrutura ou acontecimento. Tradução de Eni Puccinelli Orlandi. Campinas: Pontes, 1983.

RANCIÈRE, Jacques. O desentendimento: política e filosofia. São Paulo: Ed. 34, 1996.

\section{Filmografia}

Título em português: Furyo: em nome da honra

Título em Japonês: Senjō no merii kurisumasu

Ano: 1982

Direção: Nagisa Oshima

Produção: Jeremy Thomas

Elenco: Ryuichi Sakamoto, Takeshi Kitano, David Bowie, Tom Conti, Jack Thompson

Direção de fotografia: Toichiro Narushima

Produção de arte: Jusho Toda

Música: Ryuichi Sakamoto

Produtor Associado: Joyce Herlihy

Produção executiva: Masato Hara, Eiko Oshima, Geoffrey Nethercotto, Terry Glinwood.

Roteiro: Nagisa Oshima, Paul Mayersberg

Baseado no romance: The seed and the sower (Sir Laurens Van der Post) 